\title{
Heart Rate and Oxygen Saturation Monitoring With a New Wearable Wireless Device in the Intensive Care Unit: Pilot Comparison Trial
}

Srinivasan Murali $^{1 *}, \mathrm{PhD}$; Francisco Rincon ${ }^{1 *}, \mathrm{PhD}$; Tiziano Cassina ${ }^{2}, \mathrm{MD}$; Stephane Cook $^{3 *}$, MD; Jean-Jacques $\mathrm{Goy}^{3}, \mathrm{MD}$

\footnotetext{
${ }^{1}$ SmartCardia, Lausanne, Switzerland

${ }^{2}$ Cardiocentro, Lugano, Switzerland

${ }^{3}$ University Hospital Fribourg, Fribourg, Switzerland

*these authors contributed equally
}

\section{Corresponding Author:}

Jean-Jacques Goy, MD

University Hospital Fribourg

Rue des Pensionnats 5-7

Fribourg,

Switzerland

Phone: 41792136465

Email: jigoy@goyman.com

\section{Abstract}

Background: Continuous cardiac monitoring with wireless sensors is an attractive option for early detection of arrhythmia and conduction disturbances and the prevention of adverse events leading to patient deterioration. We present a new sensor design (SmartCardia), a wearable wireless biosensor patch, for continuous cardiac and oxygen saturation $\left(\mathrm{SpO}_{2}\right)$ monitoring.

Objective: This study aimed to test the clinical value of a new wireless sensor device (SmartCardia) and its usefulness in monitoring the heart rate $(\mathrm{HR})$ and $\mathrm{SpO}_{2}$ of patients.

Methods: We performed an observational study and monitored the $\mathrm{HR}$ and $\mathrm{SpO}_{2}$ of patients admitted to the intensive care unit (ICU). We compared the device under test (SmartCardia) with the ICU-grade monitoring system (Dräger-Healthcare). We defined

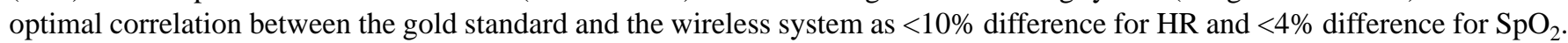
Data loss and discrepancy between the two systems were critically analyzed.

Results: A total of 58 ICU patients (42 men and 16 women), with a mean age of 71 years (SD 11), were included in this study. A total of 13.49 (SD 5.53) hours per patient were recorded. This represents a total recorded period of 782.3 hours. The mean difference between the HR detected by the SmartCardia patch and the ICU monitor was 5.87 (SD 16.01) beats per minute (bias=-5.66, SD 16.09). For $\mathrm{SpO}_{2}$, the average difference was 3.54\% (SD 3.86; bias=2.9, SD 4.36) for interpretable values. SmartCardia's patch measures $\mathrm{SpO}_{2}$ only under low-to-no activity conditions and otherwise does not report a value. Data loss and noninterpretable values of $\mathrm{SpO}_{2}$ represented 26\% (SD 24) of total measurements.

Conclusions: The SmartCardia device demonstrated clinically acceptable accuracy for $\mathrm{HR}$ and $\mathrm{SpO}_{2}$ monitoring in ICU patients.

(JMIR Biomed Eng 2020;5(1):e18158) doi: 10.2196/18158

\section{KEYWORDS}

cardiac monitoring; wireless monitor; wearable; cardiology; ICU; respiratory monitoring

\section{Introduction}

Electrocardiogram (ECG) monitoring in hospital units and intensive care units (ICU) has been performed for 50 years [1]. The goals of monitoring have changed over time, from simple tracking of heart rate (HR) and basic rhythm to the diagnosis of complex arrhythmias, detection of myocardial ischemia, identification of prolonged QT interval, or modifications of the QRS complex. Continuous ECG monitoring assists physicians in the evaluation of patients. Vital signs are usually measured 
and documented by nurses. The frequency of measurements is increased when necessary, and, in the event of aberrant signs, the physician is informed and nurses manually check patient vital signs, sometimes with poor compliance $[2,3]$. This practice has several potential weaknesses. The frequency of monitoring by nurses is low, and relevant changes in vital signs may remain undetected, especially when they are subtle or within the normal range. These could lead to adverse events or complications [4].

Over time, major improvements have been made in cardiac monitoring systems, including computerized arrhythmia detection algorithms, ST segment/ischemia monitoring software, improved noise reduction strategies, multileads monitoring, reduced lead sets for monitoring-derived 12-lead ECG, wireless transmission of information and centralized data collection, all with a minimal number of electrodes [5,6]. With the introduction of wireless sensors that allow wireless continuous monitoring, an improvement in patient safety can be achieved [7]. Recently, the accuracy of wireless systems with different sensing principles was validated [8] in high-risk patients. Some of these devices are Food and Drug Administration (FDA)- or Conformité Européene (CE)-approved. It is hoped that these wireless systems can keep the alarm range as low as possible to reduce alarm fatigue that may otherwise result in alarm desensitization. New systems should be able to identify changes in patients' values when an adverse event develops. However, no system presently meets all these criteria. Wireless devices improve continuous monitoring and outcomes in hospital wards, as demonstrated recently [8-10]. Wireless systems now provide $\mathrm{HR}$ monitoring and oxygen saturation $\left(\mathrm{SpO}_{2}\right)$ measurements. HR monitoring is obtained with adhesive patches. In some instances, these systems can detect arrhythmias at better rates than Holter monitoring. Ventilatory frequency and $\mathrm{SpO}_{2}$ measurements are of crucial importance in patient monitoring on hospital wards. Clinical deterioration of patients with hypoxemia and hypotension can be missed with typical ward monitoring, which is performed every 2-6 hours. In recent studies, routine checking of vital signs every 4 hours missed $90 \%$ of patients with at least 15 minutes of $\mathrm{SpO}_{2}<90 \%$ [11]. Ventilatory frequency can also be derived from wireless pulse oximeters and chest patch systems that sense respiratory variation in R-wave amplitude and RR intervals. We designed a pilot trial to assess the safety and validity of an innovative wireless device, SmartCardia, in monitoring patients hospitalized in the ICU.

\section{Methods}

\section{Study Design}

This is a descriptive trial analysis of vital signs during hospitalization in a subset of patients, most of whom were being treated for cardiac disease. ICU patients at the Cardiocentro Ticino Hospital (Lugano, Ticino, Switzerland) were included in the trial. They were monitored with a medically approved existing monitoring system designated as the gold standard system (Dräger-Healthcare). In addition, the innovative wireless equipment (SmartCardia) was used to record ECG and $\mathrm{SpO}_{2}$ for the duration of the patient's stay in the ICU. The study was designed as a pilot trial. We chose patients in the ICU because they are monitored 24 hours a day, making comparison with our device easier. This study is a first step prior to testing the device as a telemetry system or for 24-hour outpatient monitoring. Although the device was designed to detect arrhythmia, this feature was not tested in this trial. We deliberately decided to first confirm a high level of reliability and therefore focused on $\mathrm{HR}$ and $\mathrm{SpO}_{2}$ in this study. This corresponds to a validation of the device for $\mathrm{HR}$ and $\mathrm{SpO}_{2}$ monitoring. The next step will be to test the device as an ambulatory or telemetry monitoring device.

\section{Study Population}

Patients scheduled for major surgery or hospitalized in the ICU with an indication for cardiac and respiratory monitoring were asked to participate. Patients with an implantable cardiac device as well as those allergic to adhesive or with thorax skin irritation were excluded.

The inclusion criteria were as follows:

1. Patients with cardiovascular disease admitted to Cardiocentro's ICU, and aged 16 years and above

2. Patients who voluntarily signed informed consent forms

3. Postsurgery patients with stable hemodynamic condition

4. Postmyocardial infarction patients with stable hemodynamic condition

5. ICU patients who need continuous monitoring of vital signs for at least $12 \mathrm{~h}$. The patients were not consecutive patients, and they were fully immobilized in their bed.

\section{Informed Consent and Data Collection}

This protocol was approved by the local ethics committee, and written informed consent of all patients was obtained. Data were collected anonymously and transferred to SmartCardia for a blinded analysis.

\section{System Description}

The system is a wireless patch with a low-cost disposable component and a rechargeable/reusable electronic unit (dimensions $65 \mathrm{~mm} \times 125 \mathrm{~mm}$; Figure 1). The patch measures a single-lead ECG, HR, HR variability, respiration rate, oxygen saturation, skin temperature, posture, activity, and blood pressure variations. The data are transmitted by Bluetooth to a mobile phone or router. The measured signals and parameters are also stored on the device. The device is placed on the left upper portion of the patient's chest (Figure 2). The patch-based device offers up to 7-day data storage and 3.5-day real-time connectivity through a smartphone connected to cloud storage on a single battery charge. The ability to receive, store, and interpret a broad range of parameters offers the opportunity to go far beyond monitoring individual parameters. In this study, the ECG-based $\mathrm{HR}$ and $\mathrm{SpO}_{2}$ measurements taken by the SmartCardia device were compared with the measurements obtained by the standard monitoring system used in the ICU. 
Figure 1. The appearance and dimensions of the SmartCardia wireless device.

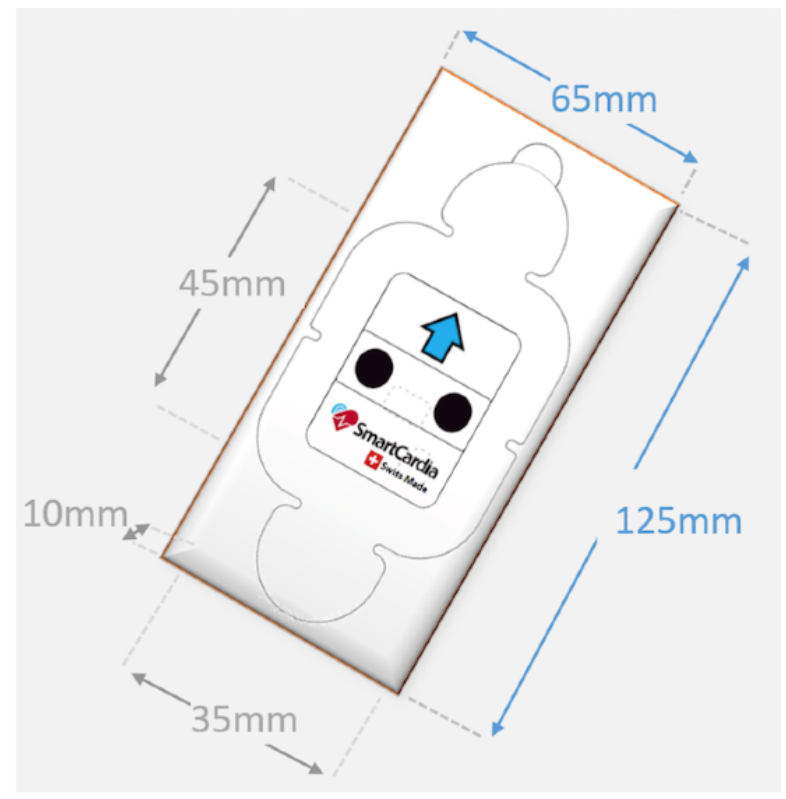

Figure 2. Device on the chest of the patient.

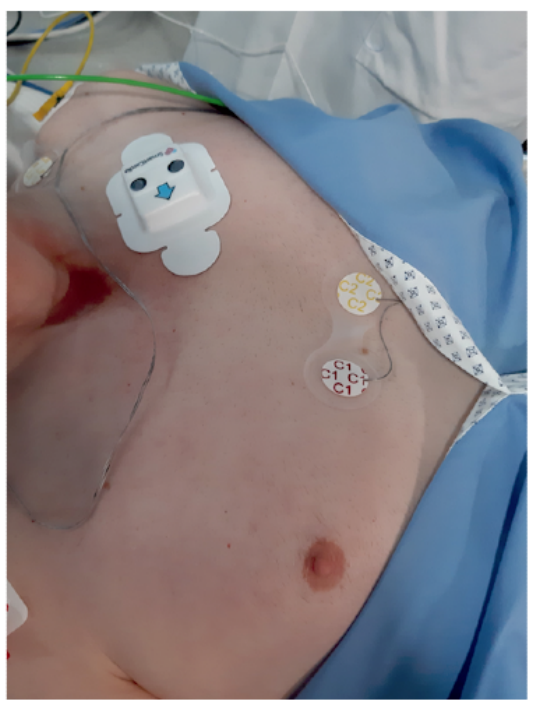

\section{Safety}

The materials and the patches that have skin contact meet the ISO 10993 guidelines, specifically the criteria for skin irritation, skin sensitization, and in vitro cytotoxicity.
Two SmartCardia patches were attached to the chest and the left arm, respectively, of the patient (Figure 2). A high-quality ECG signal is recorded with the chest device (Figure 3), while the arm device records the best oxygen saturation signal.

Figure 3. Typical trace recorded with the SmartCardia device.

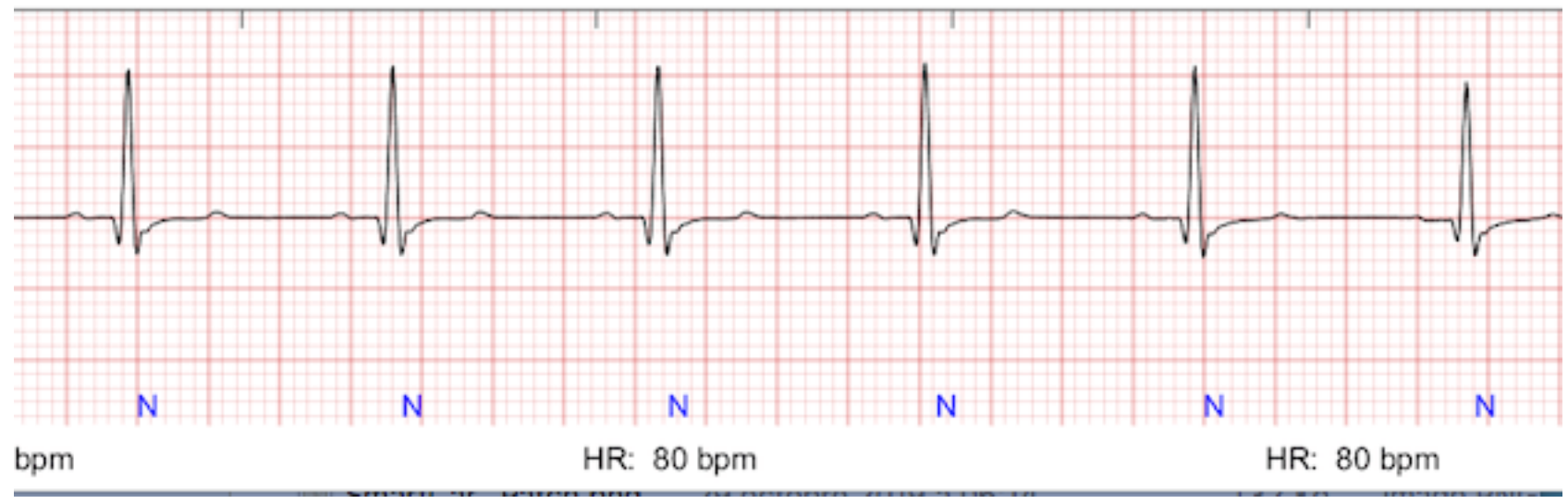




\section{Endpoints}

The endpoints of this pilot trial were the following: safety of the wireless device, tolerance of the device, correlation of HR measurements obtained by the wireless device and the conventional monitoring device, and correlation of $\mathrm{SpO}_{2}$ measurements obtained by the wireless device and the conventional monitoring device.

\section{Statistics}

Sample size could not be calculated, as no power calculations exist in the literature. Data pairs of $\mathrm{HR}$ and $\mathrm{SpO}_{2}$ measurements were analyzed with the Bland and Altman method, as suggested by Breteler et al $[7,12]$. This method was used to account for within-subject variations by correcting the differences between the average differences. Bias between the reference monitor and the sensor, with its $95 \%$ limits, was determined for both $\mathrm{HR}$ and $\mathrm{SpO}_{2}$. The correlation between the two systems was considered optimal when the mean HR differed by $<5$ beats per minute or $<10 \%$ and when $\mathrm{SpO}_{2}$ variations were $<4 \%$.

The Clarke Error Grid was used to determine the clinical accuracy of the wireless sensor compared with the reference standard [11]. Performance was analyzed by the percentage of data that was lost or noninterpretable.

\section{Results}

During the study period (May 17, 2017, to March 31, 2018), 58 patients (42 men and 16 women), with a mean age of 71 (SD 11) years, were included in this prospective pilot trial (Table 1). Patients mainly had heart problems and were hospitalized in the ICU after cardiac surgery $(n=39,67 \%)$, transaortic valvular implantation $(\mathrm{n}=14,24 \%)$, acute coronary syndrome (ACS, $n=3,5 \%$ ), aggravation of chronic obstructive pulmonary disease (COPD, $n=1,2 \%$ ), and out of hospital cardiac arrest $(n=1,2 \%)$. The recording could be achieved in all patients. No patients reported side effects (such as skin rash) from the SmartCardia device. There was no disconnection of the device or interruption of the recording due to poor skin contact.
Total monitoring time is displayed in Table 2 and was $782 \mathrm{~h} 17$ min (mean $809 \mathrm{~min} /$ patient, SD 332) for the chest device and $794 \mathrm{~h} 22 \mathrm{~min}$ for the arm device (mean $822 \mathrm{~min} /$ patient, SD 322).

The correlation rate for the ECG signal between the two systems was $97.6 \%$ for the total recorded values (Figure 4). In 10 patients (17\%), correlation between the two systems was $<95 \%$ (Figure $5)$.

Table 3 shows the bias and precision (95\% agreement) between $\mathrm{HR}$ and $\mathrm{SpO}_{2}$ measurements, respectively, by the wireless device and the gold standard. The $95 \%$ limit of agreement was calculated with the Bland-Altman method (HR: Figure 6; $\mathrm{SpO}_{2}$ : Figure 7).

The causes for instances of low correlation between the two systems included (1) failure of the gold standard in 2 cases (disconnection of one cable); (2) failure of the SmartCardia device due to poor skin contact or bad positioning in 4 patients (solved by reapplication or repositioning); (3) overdetection of the $\mathrm{T}$ wave as a QRS complex, inducing double count in 2 patients (Figures 8 and 9); and (4) technical failure of the SmartCardia device in 2 patients (memory corruption in one case and a casing mechanical issue in the other).

The mean exact correlation rate for $\mathrm{SpO}_{2}$ measurement $(<4 \%$ difference) was obtained in $44 / 58$ patients ( $75 \%$; Table 2$)$. A correlation between $5 \%$ and $6 \%$ of exact correlation was obtained in 4 patients (7\%). Finally, in 10 patients $(18 \%)$, the correlation rate was considered low ( $>6 \%$ of error) and the largest difference was $14 \%$.

The Clarke Error Grid analysis was used to quantify the clinical accuracy of the $\mathrm{HR}$ and $\mathrm{SpO}_{2}$ measurements obtained by the wireless system. This information is shown in Table 4 and plotted in Figures 10 and 11. The percentage of data pairs in regions $\mathrm{A}$ to $\mathrm{E}$ are shown in Table 4. For HR, $96.2 \%$ of the values are in regions $\mathrm{A}$ and $\mathrm{B}$. For $\mathrm{SpO}_{2}, 100 \%$ of the points are in regions $\mathrm{A}$ and $\mathrm{B}$.

Table 1. Demographics of the patients included in the trial.

\begin{tabular}{lll}
\hline Demographic & Male $(\mathrm{n}=42)$ & Female $(\mathrm{n}=16)$ \\
\hline Age (years), mean (SD) & $70(12)$ & $74(8)$ \\
Trans-aortic valvular implantation, $\mathrm{n}(\%)$ & $10(24)$ & $4(25)$ \\
Coronary artery bypass grafting, $\mathrm{n}(\%)$ & $21(50)$ & $8(50)$ \\
Open-heart valvular surgery, $\mathrm{n}(\%)$ & $6(14)$ & $4(25)$ \\
ST segment elevation myocardial infarction and ischemic heart disease, $\mathrm{n}(\%)$ & $3(7)$ & $0(0)$ \\
Chronic obstructive pulmonary disease, $\mathrm{n}(\%)$ & $1(2)$ & $0(0)$ \\
Cardiac arrest, $\mathrm{n}(\%)$ & $1(2)$ & $0(0)$ \\
\hline
\end{tabular}


Table 2. Recording results and correlation rates.

\begin{tabular}{lll}
\hline Parameter & Heart rate monitoring $(\mathrm{n}=58)$ & Oxygen saturation monitoring $(\mathrm{n}=58)$ \\
\hline Total monitoring time & $782 \mathrm{~h} 17 \mathrm{~min}$ & $794 \mathrm{~h} 22 \mathrm{~min}$ \\
Monitoring time per patient (min) & $822(\mathrm{SD} 332)$ & 809 (SD 332) \\
Exact value (<5\% error), $\mathrm{n}(\%)$ & $48(83)$ & $44(75)$ \\
Values in the 5\%-6\% error range, $\mathrm{n}(\%)$ & $2(4)$ & $4(7)$ \\
Values $>6 \%$ error, $\mathrm{n}(\%)$ & $8(14)$ & $10(18)$ \\
\hline
\end{tabular}

Figure 4. Recordings by the two monitoring systems, showing extremely good correlation (blue = SmartCardia recording; black = conventional monitoring).

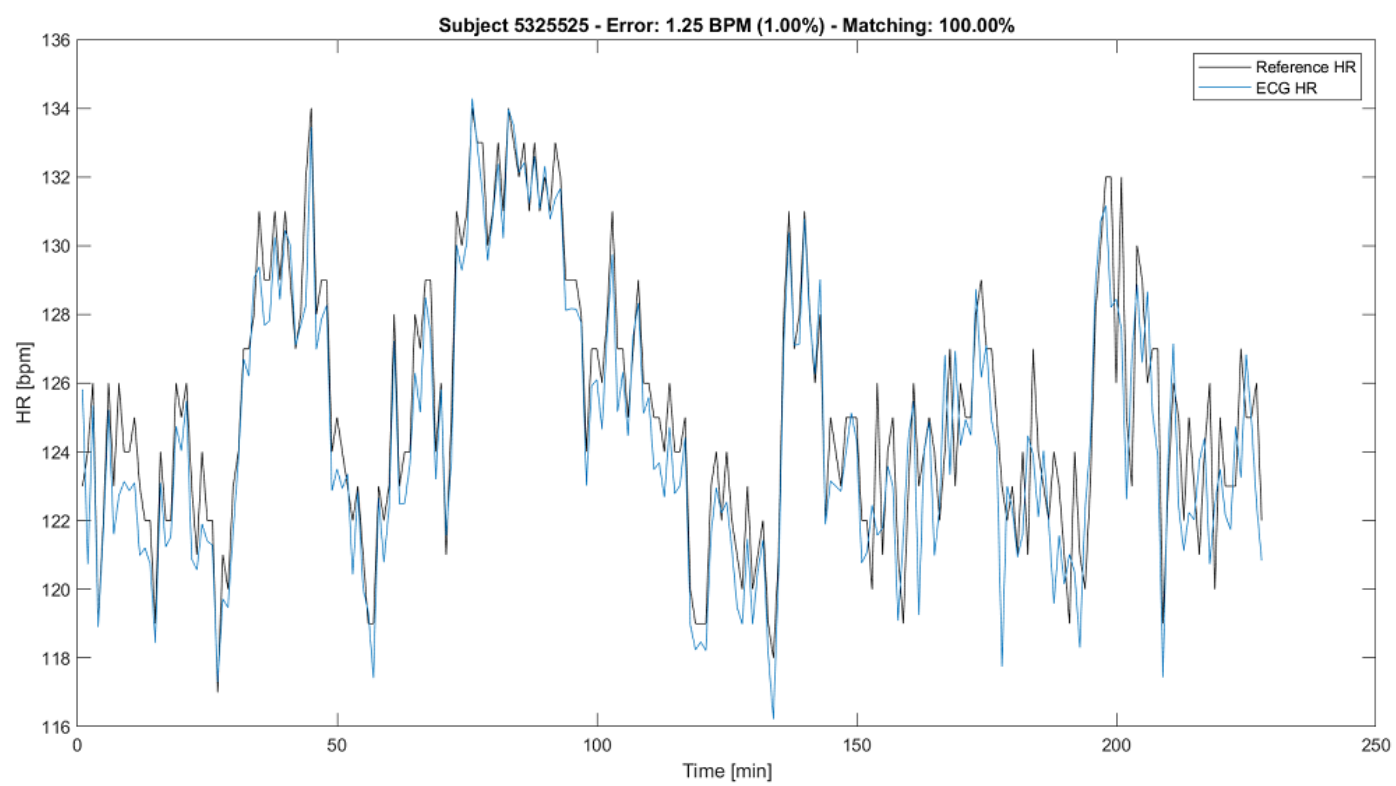

Figure 5. Example of a trace defined as exact. Some PVB (premature ventricular beats) are correctly detected by the wireless system where the gold standard failed.

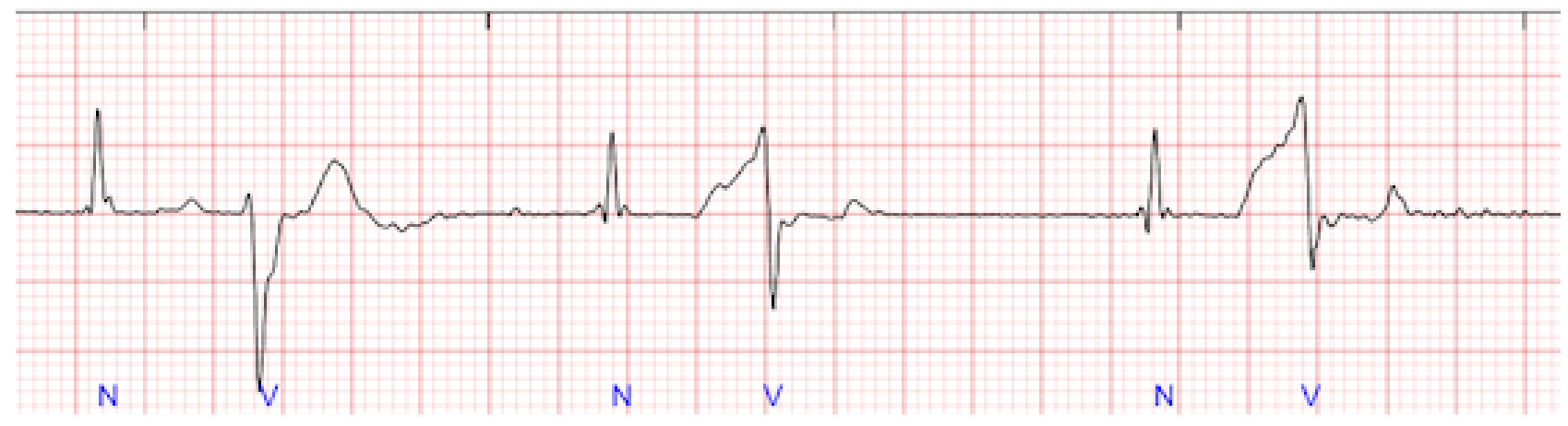

HR: 78 bpm

HR: $85 \mathrm{bpm}$

Table 3. Bland-Altman analysis of heart rate and oxygen saturation.

\begin{tabular}{|c|c|c|c|c|c|c|}
\hline $\begin{array}{l}\text { Parameters } \\
\text { measured }\end{array}$ & Number of measurement pairs & $\begin{array}{l}\text { Number of pa- } \\
\text { tients }\end{array}$ & Bias, n (SD) & $\begin{array}{l}\text { Average absolute error, } \mathrm{n} \\
\text { (SD) }\end{array}$ & Lower $95 \%$ & $\begin{array}{l}\text { Upper } \\
95 \%\end{array}$ \\
\hline Heart rate & 41283 & 58 & $-5.66(16.09)$ & $5.87(16.01)$ & -37.19 & 25.87 \\
\hline $\begin{array}{l}\text { Oxygen satura- } \\
\text { tion }\end{array}$ & 58970 & 58 & $2.9(4.36)$ & $3.54(3.86)$ & -5.65 & 11.45 \\
\hline
\end{tabular}


Figure 6. Bland-Altman plots of heart rate for the wireless system. Y-axis = difference between Smart-Cardia device and reference.

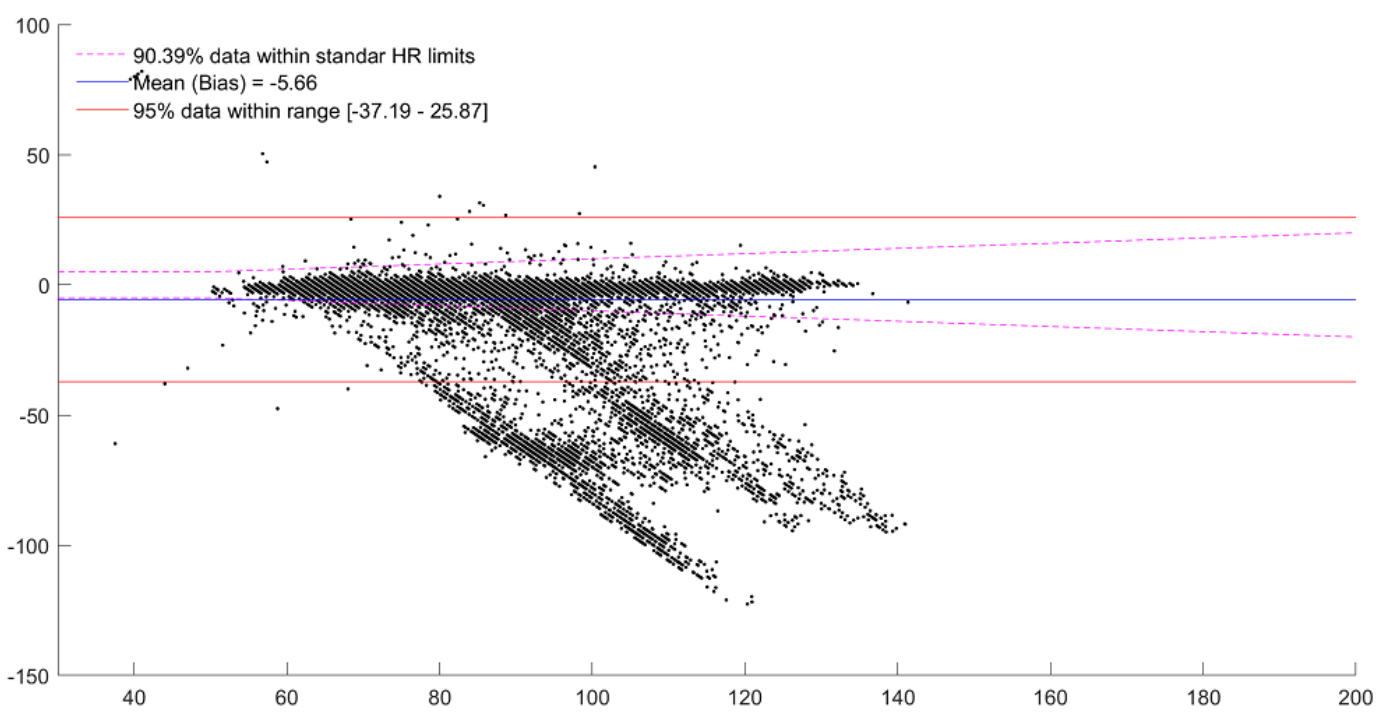

Figure 7. Bland-Altman plots of oxygen saturation measurements by the wireless system. Y-axis = difference between Smart-Cardia device and reference.

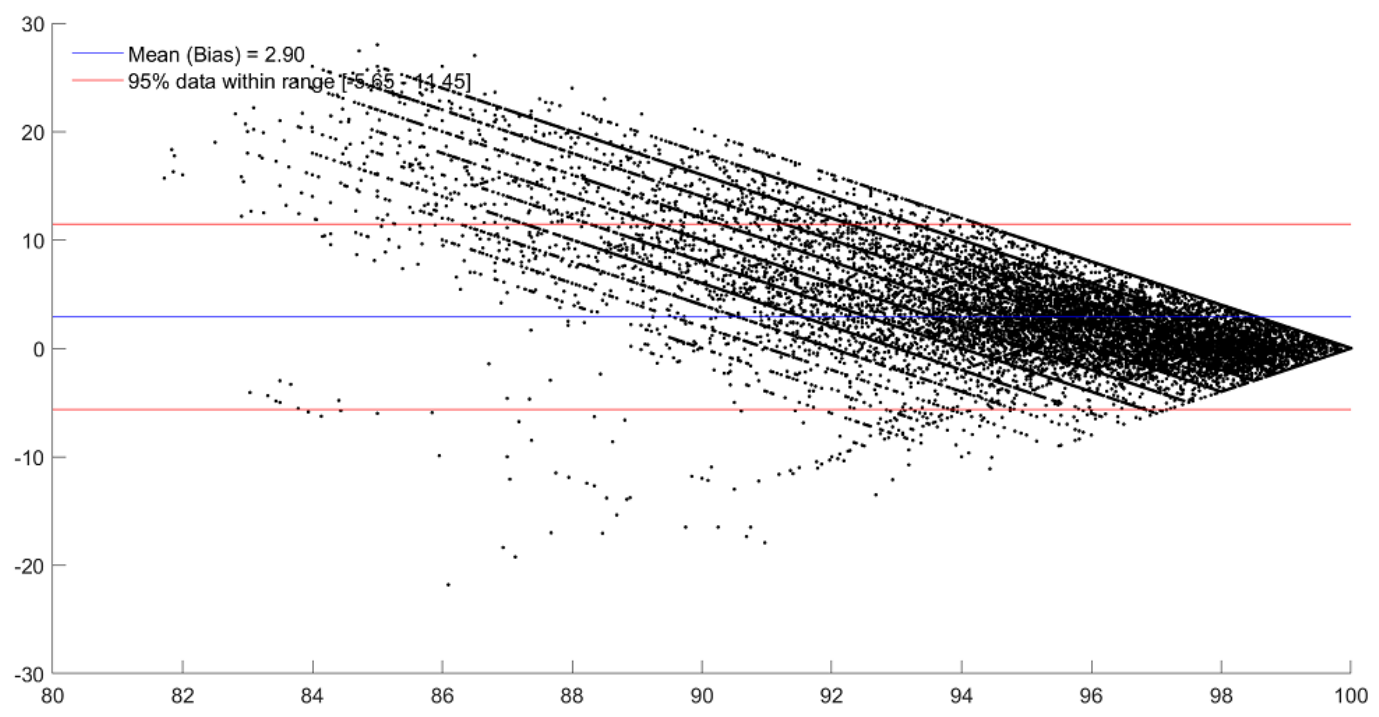

Figure 8. Example of a trace qualified as "non exact". The T wave has been included in the heart rate count, doubling the value to $126 \mathrm{bpm}$ from 63 bpm.

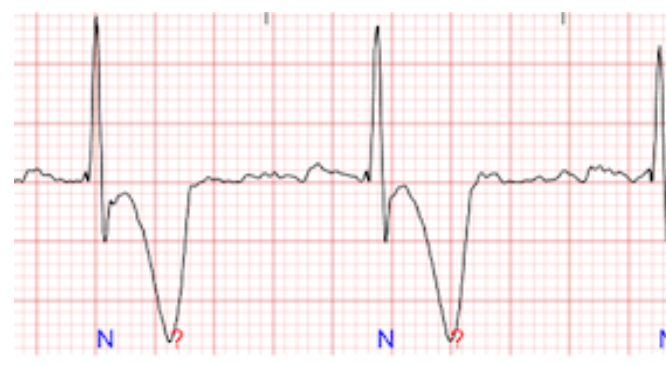

HR: 126 bpm

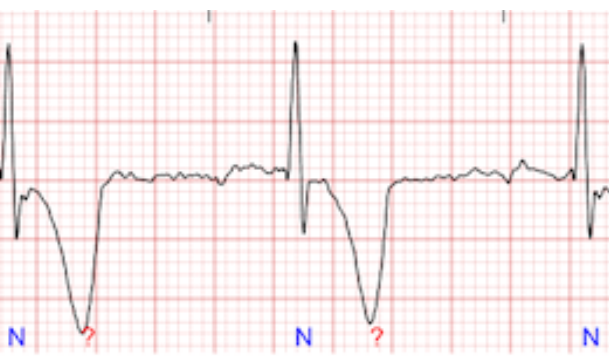

HR: 126 bpm

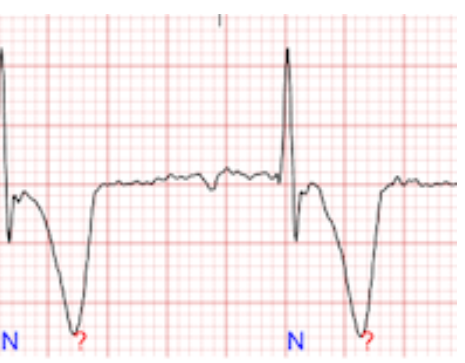

HR: 126 bpm 
Figure 9. Discrepancy between the two monitoring systems, lasting a few hours, due to double counting by the SmartCardia device (SmartCardia heart rate values were double that of the gold standard). This was due to $\mathrm{Q}$ wave detection being counted as a QRS complex.

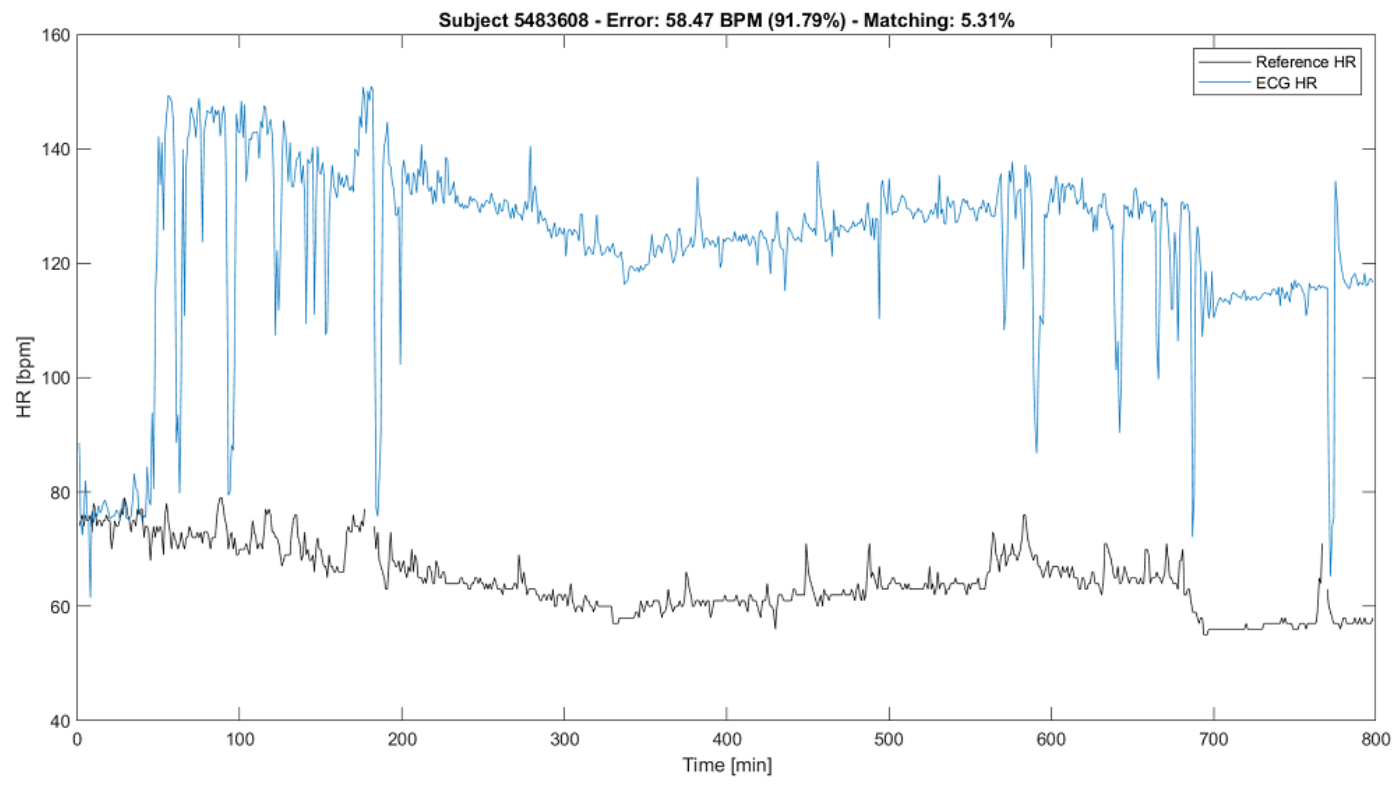

Table 4. Clarke Error Grid analysis to quantify the clinical accuracy of heart rate and oxygen saturation.

\begin{tabular}{llllll}
\hline Parameters measured & $\begin{array}{l}\text { Measurements in region } \\
\mathrm{A}, \mathrm{n}(\%)\end{array}$ & $\begin{array}{l}\text { Measurements in region } \\
\mathrm{B}, \mathrm{n}(\%)\end{array}$ & $\begin{array}{l}\text { Measurements in region } \\
\mathrm{C}, \mathrm{n}(\%)\end{array}$ & $\begin{array}{l}\text { Measurements in re- } \\
\text { gion D, n (\%) }\end{array}$ & $\begin{array}{l}\text { Measurements in re- } \\
\text { gion E, } \mathrm{n}(\%)\end{array}$ \\
\hline Heart rate & $38133(92)$ & $1743(4.2)$ & $1553(3.7)$ & $5(0.1)$ & $0(0)$ \\
Oxygen saturation & $58414(69)$ & $26133(30.9)$ & $0(0)$ & $0(0)$ & $0(0)$ \\
\hline
\end{tabular}

Figure 10. Clarke Error Grid analysis to quantify the clinical accuracy of heart rate measurements by the Smart Cardia device. Region A contains $92 \%$ of recorded values, indicating a high accuracy of measurements. Regions D and E represent regions with unacceptable accuracy and only $0.1 \%$ of values were in these regions.

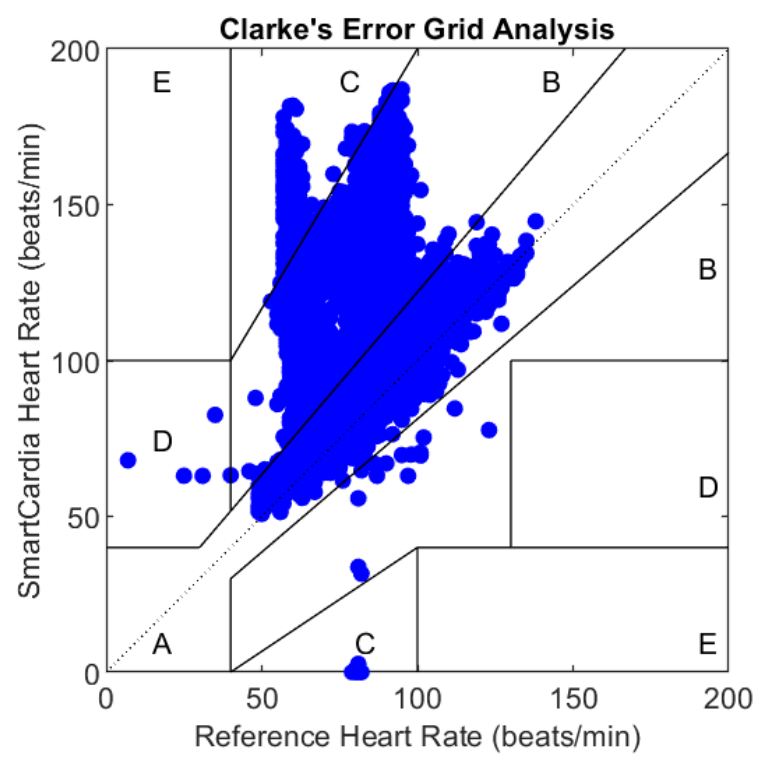


Figure 11. Clarke Error Grid analysis to quantify the clinical accuracy of oxygen saturation measurements taken by the SmartCardia device. Region A and B contain $96 \%$ of values within the limit range.

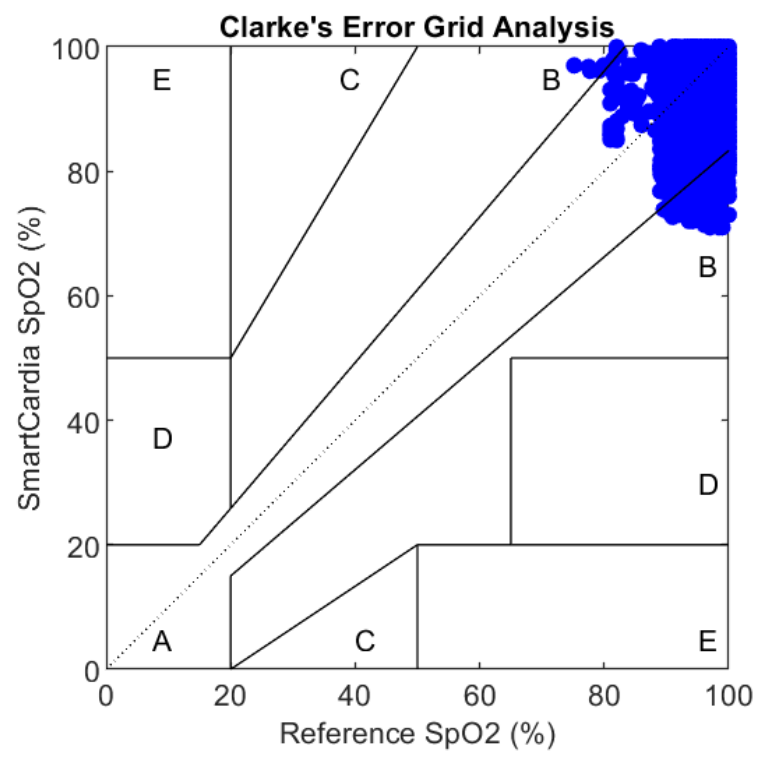

\section{Discussion}

\section{Principal Findings}

Monitoring is a critical issue in the ICU and intermediate care units during the first days following the intervention. Today, cardiac monitoring is carried out with skin electrodes. The signal is transmitted by wires to a bedside monitor and a central station. In this pilot trial, we tested the ability of a new wireless vital sign sensor to monitor patients. The first generation of wireless sensors was shown to be useful in the detection of abnormalities in vital signs, sometimes preceding adverse events [7-15]. It is well accepted that early detection of arrhythmias is important since they can precede serious complications in patients in the ICU or general ward $[14,15]$. The quality of the signal is dependent on the physical device connections and good contact between electrodes and the patient's skin. Monitoring of $\mathrm{SpO}_{2}$ is usually performed using a system attached to the finger of the patient, with a cable transmission to the central station. Recently, wireless monitoring has been confirmed as a valuable tool to detect adverse events in high-risk patients [4-6]. A recent study showed significant differences between different wireless sensors [8]. For example, the Radius-7 (Masimo) underestimates $\mathrm{HR}$, as it calculates HR from the plethysmographic waveform obtained from the pulse oximeter probe. The EarlySense system may also underestimate HR during periods of arrhythmia, as it derives HR from cardiac ballistic movement associated with the ejection of blood with each heart cycle. During a rapid ventricular rate, some beats will not be long enough to allow for ventricular filling and will therefore not result in a detectable peripheral pulse. SmartCardia's patch measures and stores ECG data and parameters for up to 7 days on a single charge. A comparison of ECG patches by Sensium and VitalConnect [8] showed that they both have a limited storage capacity of 10 hours or less. Additionally, these patches do not measure $\mathrm{SpO}_{2}$, while this study demonstrated the feasibility of measuring both $\mathrm{SpO}_{2}$ and $\mathrm{HR}$ with the SmartCardia patch $[16,17]$.
The benefits of patient monitoring with wireless sensors have been shown [18-21]. To be useful for patient management after major surgical interventions, reliable wireless sensors must be connected to a central system with alarm notification. False alerts should be avoided to increase the reliability of the monitoring system.

The new wireless SmartCardia device, tested in this trial, is a combined system allowing monitoring of both $\mathrm{HR}$ and $\mathrm{SpO}_{2}$. The recording system is in a small patch-box that is adhered to the patient's skin without wires, avoiding undesired problems related to wire disconnection. In addition, it is user-friendly in terms of installation. Transportation of the patient is also facilitated without the need to disconnect and reconnect wires.

This study was mainly designed to validate the sensor accuracy of the SmartCardia system, not to clinically monitor patients in the ICU. Thus, the sample size is rather small, and the number of events was too small to identify specific signs or patterns of adverse events. However, our results do provide insight into the ability of wireless sensors to assist in patient monitoring and early detection of patient deterioration.

In this pilot trial, we showed that the HR data obtained with the SmartCardia device is of good quality as compared with the gold standard monitoring system. We identified that both this new system and the gold standard system can fail. The major problem identified with this first generation of the SmartCardia system is maintaining adequate skin contact. With further technical improvements, this problem has been solved, leading to $100 \%$ success in device attachment. We also noted that optimal positioning of the device on the patient's chest is of crucial importance. In the small number of patients with poor recording quality, the device was not positioned correctly. Better placement of the device allowed significant improvement of the recording. We also noted that in 2 patients, a technical problem of the SmartCardia device was the reason for failure. We identified this problem and improvements were made in the most recent generation of devices. 


\section{Limitations}

The main limitation of this trial is the relatively small number of patients. In addition, it has only been tested in patients hospitalized in the ICU. Tests in postoperative patients in the ward must be realized.

\section{Conclusion}

We demonstrated that a new wireless device provides good quality HR measurements in patients in the ICU. Furthermore, $\mathrm{SpO}_{2}$ monitoring is feasible, although further technical improvements are mandatory. Based on these results, further trials should be performed in an outpatient population to define the place of such devices in daily practice. Finally, it should be compared with conventional Holter monitoring.

\section{Conflicts of Interest}

SM and FR are part of the board of SmartCardia.

\section{References}

1. Day HW. Preliminary studies of an acute coronary care area. Lancet 1963;83:53-55. [Medline: 14025617]

2. Ludikhuize J, Smorenburg SM, de Rooij SE, de Jonge E. Identification of deteriorating patients on general wards; measurement of vital parameters and potential effectiveness of the Modified Early Warning Score. Journal of Critical Care 2012;27(4):424.e7-424.e13. [doi: 10.1016/j.jcrc.2012.01.003]

3. Cardona-Morrell M, Prgomet M, Lake R, Nicholson M, Harrison R, Long J, et al. Vital signs monitoring and nurse-patient interaction: A qualitative observational study of hospital practice. International Journal of Nursing Studies 2016;56:9-16. [doi: 10.1016/j.ijnurstu.2015.12.007]

4. Dower GE, Yakush A, Nazzal SB, Jutzy RV, Ruiz CE. Deriving the 12-lead electrocardiogram from four (EASI) electrodes. Journal of Electrocardiology 1988;21:S182-S187. [doi: 10.1016/0022-0736(88)90090-8]

5. Drew BJ, Pelter MM, Brodnick DE, Yadav AV, Dempel D, Adams MG. Comparison of a new reduced lead set ECG with the standard ECG for diagnosing cardiac arrhythmias and myocardial ischemia. Journal of Electrocardiology 2002;35(4):13-21. [doi: 10.1054/jelc.2002.37150]

6. Downey C, Randell R, Brown J, Jayne DG. Continuous Versus Intermittent Vital Signs Monitoring Using a Wearable, Wireless Patch in Patients Admitted to Surgical Wards: Pilot Cluster Randomized Controlled Trial. J Med Internet Res 2018 Dec 11;20(12):e10802. [doi: 10.2196/10802]

7. Breteler MJM, KleinJan EJ, Dohmen DAJ, Leenen LPH, van Hillegersberg R, Ruurda JP, et al. Vital Signs Monitoring with Wearable Sensors in High-risk Surgical Patients. Anesthesiology 2020;132(3):424-439. [doi: 10.1097/aln.0000000000003029]

8. Breteler MJM, KleinJan E, Numan L, Ruurda JP, Van Hillegersberg R, Leenen LPH, et al. Are current wireless monitoring systems capable of detecting adverse events in high-risk surgical patients? A descriptive study. Injury 2019 Nov 17 [FREE Full text] [doi: 10.1016/j.injury.2019.11.018] [Medline: 31761422]

9. Michard F, Teboul JL. Predictive analytics: beyond the buzz. Ann Intensive Care 2019 Apr 11;9(1). [doi: 10.1186/s13613-019-0524-9]

10. Sessler DI, Saugel B. Beyond 'failure to rescue': the time has come for continuous ward monitoring. British Journal of Anaesthesia 2019 Mar;122(3):304-306. [doi: 10.1016/j.bja.2018.12.003]

11. Clarke WL, Cox D, Gonder-Frederick LA, Carter W, Pohl SL. Evaluating Clinical Accuracy of Systems for Self-Monitoring of Blood Glucose. Diabetes Care 1987 Sep 01;10(5):622-628. [doi: 10.2337/diacare.10.5.622]

12. Altman DG, Bland JM. Measurement in Medicine: The Analysis of Method Comparison Studies. The Statistician 1983 Sep;32(3):307. [doi: 10.2307/2987937]

13. Selvaraj N, Nallathambi G, Moghadam R, Aga A. Fully Disposable Wireless Patch Sensor for Continuous Remote Patient Monitoring. 2018 Presented at: 40th Annual International Conference of the IEEE (IMBS); 20-21 July; Honolulu. [doi: $10.1109 / \mathrm{embc} .2018 .8512569]$

14. Selvaraj N, Nallathambi G, Kettle P. A Novel Synthetic Simulation Platform for Validation of Breathing Rate Measurement. 2018 Presented at: 40th Annual International Conference of the IEEE (IMBS); July; Honolulu. [doi:

10.1109/embc.2018.8512352]

15. Seesing M. F. J., Scheijmans, J.C.G., Borggreve, A.S., van Hillegersberg, R., Ruurda, J. P. The predictive value of new-onset atrial fibrillation on postoperative morbidity after esophagectomy. Dis Esophagus Nov 1 2018;31:11. [doi: 10.1093/dote/doy028]

16. Chan AM, Ferdosi N, Narasimhan R. Ambulatory respiratory rate detection using ECG and a triaxial accelerometer. 2013 Presented at: Conf Proc IEEE Eng Med Biol Soc; 2013; Atlanta p. 4058-4061. [doi: 10.1109/embc.2013.6610436]

17. Hernandez-Silveira M, Ahmed K, Ang S, Zandari F, Mehta T, Weir R, et al. Assessment of the feasibility of an ultra-low power, wireless digital patch for the continuous ambulatory monitoring of vital signs. BMJ Open 2015 May 19;5(5):e006606-e006606. [doi: 10.1136/bmjopen-2014-006606]

18. Weenk M, Koeneman M, van de Belt TH, Engelen LJ, van Goor H, Bredie SJ. Wireless and continuous monitoring of vital signs in patients at the general ward. Resuscitation 2019 Mar;136:47-53. [doi: 10.1016/j.resuscitation.2019.01.017] 
19. Gardner-Thorpe J, Love N, Wrightson J, Walsh S, Keeling N. The Value of Modified Early Warning Score (MEWS) in Surgical In-Patients: A Prospective Observational Study. Ann R Coll Surg Engl 2006 Oct;88(6):571-575. [doi: $10.1308 / 003588406 \times 130615]$

20. Posthuma LM, Visscher MJ, Hollmann MW, Preckel B. Monitoring of High- and Intermediate-Risk Surgical Patients. Anesthesia \& Analgesia 2019;129(4):1185-1190. [doi: 10.1213/ane.0000000000004345]

21. Vincent J, Einav S, Pearse R, Jaber S, Kranke P, Overdyk FJ, et al. Improving detection of patient deterioration in the general hospital ward environment. Eur J Anaesthesiol 2018 May;35(5):325-333 [FREE Full text] [doi: 10.1097/EJA.0000000000000798] [Medline: 29474347]

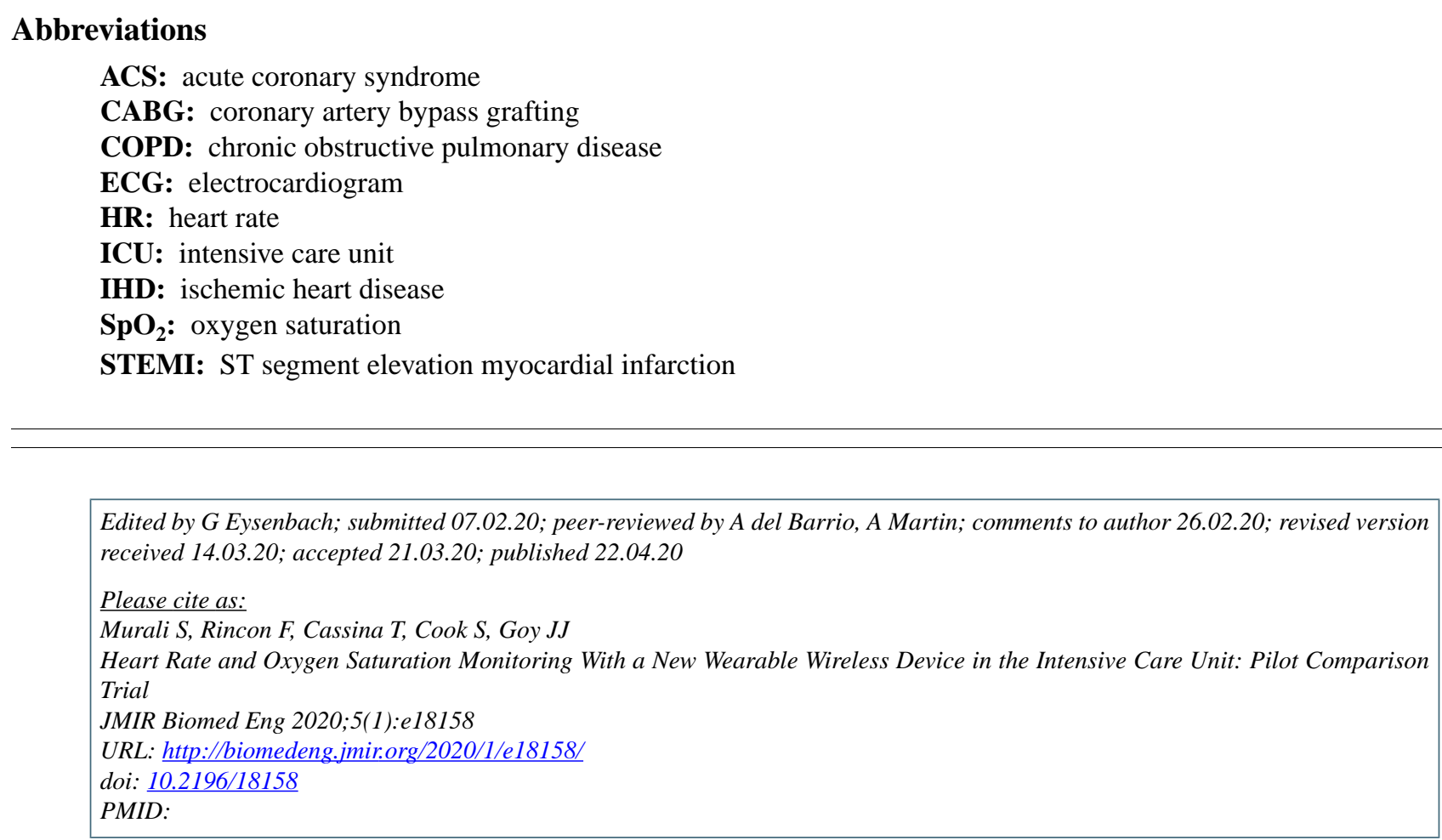

(C) Srinivasan Murali, Francisco Rincon, Tiziano Cassina, Stephane Cook, Jean-Jacques Goy. Originally published in JMIR Biomedical Engineering (http://biomedeng.jmir.org), 22.04.2020. This is an open-access article distributed under the terms of the Creative Commons Attribution License (https://creativecommons.org/licenses/by/4.0/), which permits unrestricted use, distribution, and reproduction in any medium, provided the original work, first published in JMIR Biomedical Engineering, is properly cited. The complete bibliographic information, a link to the original publication on http://biomedeng.jmir.org/, as well as this copyright and license information must be included. 